\title{
ESTUDO DA INFLUÊNCIA DO TAMANHO DE PARTÍCULA NA ADSORÇÃO DE GLICERINA POR CARVÃO ATIVADO NA PURIFICAÇÃO DE ÉSTERES ETÍLICOS DE ÓLEO DE CANOLA
}

\author{
F. G. PEREIRA ${ }^{1}$, T. R. SPARTALIS ${ }^{1}$, N. DOLFINI ${ }^{1}$, N. C. PEREIRA ${ }^{1}$ \\ e S. H. B. de FARIA ${ }^{1}$ \\ ${ }^{1}$ Universidade Estadual de Maringá, Departamento de Engenharia Química \\ E-mail para contato: felipegbl12@ gmail.com
}

\begin{abstract}
RESUMO - No presente trabalho realizou-se um estudo sobre adsorção para a remoção de glicerol proveniente do biodiesel de óleo de canola. Essa pesquisa teve como objetivo avaliar a influência do diâmetro de partícula na purificação de ésteres etílicos, utilizando carvão ativado como adsorvente. Os diâmetros médios de Sauter utilizados do carvão ativado foram de 1,21, 1,49 e 2,06 mm nos tempos de 24 e 48 horas. Os melhores resultados foram obtidos com diâmetro de 1,21 mm em 24 horas de adsorção. O método tradicional de purificação também foi realizado neste trabalho para fins comparativos. Foi possível concluir que o método de purificação por adsorção pode ser usado em substituição ao método tradicional, pois os teores de glicerol livre de ambas as metodologias $(0,018 \%$ e $0,017 \%$, respectivamente) obtidos após a purificação foram abaixo das normas especificadas pela Agência Nacional do Petróleo, Gás Natural e Biocombustíveis $(0,02 \%)$
\end{abstract}

\section{INTRODUÇÃO}

O possível esgotamento das reservas de combustíveis fósseis, associado às consequências advindas do seu uso, conduziu na consequente procura e desenvolvimento fontes de energias renováveis (SANTANA et al., 2010). O uso de óleos vegetais como combustível não é viável em equipamentos a diesel devido a fatores como alta viscosidade, conteúdo de ácidos graxos livres, combustão incompleta e baixa volatilidade. Sendo assim, há a necessidade de converter óleos vegetais em biodiesel (GERIS et al., 2007).

Segundo o Ministério da Ciência, Tecnologia e Inovação (2005), o biodiesel pode ser definido como um biocombustível derivado de óleos vegetais ou animais para uso em motores a combustão interna, a fim de substituir total ou parcialmente o óleo diesel de petróleo. São exemplos de matérias primas para a produção de biodiesel oleaginosas tais como mamona, dendê, canola, soja, amendoim, girassol e algodão, ou sebo bovino e gordura suína.

Há um incentivo especial no Brasil para o cultivo de canola, já que esta oleaginosa pode atingir teor de óleo maior que outras, como a soja, girassol e mamona. Além disso, a canola é uma alternativa interessante para a diversificação de culturas de inverno, essencial para a 
diminuição da ocorrência de pragas (MINISTÉRIO DA AGRICULTURA, 2011).

O biodiesel é proveniente da reação entre triglicerídeos e um álcool de cadeia pequena na presença de um catalisador. Os catalisadores podem ser classificados como homogêneos, heterogêneos, alcalinos, ácidos ou enzimáticos (MEHER et al., 2004).

Após a reação de transesterificação, o meio reacional contém, além do biodiesel, álcool e glicerina. Primeiro, o álcool em excesso é retirado do meio reacional, posteriormente o biodiesel é separado da glicerina. Entretanto, esta separação não é completa e por isso há a necessidade de purificação do produto, para que o mesmo atenda as normas vigentes de comércio, regulamentadas pela lei n. 45, de 26.8.2014 da Agência Nacional do Petróleo, Gás Natural e Biocombustíveis (ANP). O processo de purificação mais utilizado industrialmente é realizado por via úmida, pois a glicerina, bem como o restante de álcool no biodiesel, são solúveis em água. Contudo, este método mostra-se eficaz apenas com o uso em excesso de água, devido a formação de emulsão proveniente de saponáceos resultantes da reação (FACCINI, 2008; PAULA et al., 2011).

Devido a grande quantidade de água necessária para a purificação do biodiesel, outros métodos de purificação estão sendo desenvolvidos. Dentre eles, há o uso de adsorventes, como por exemplo, o carvão ativado, para purificar o biodiesel, pois a adsorção não gera de resíduos aquosos, remove os produtos indesejados e os adsorventes tem a possibilidade de serem reutilizados. A purificação pode ser realizada de duas formas diferentes, uma delas é o processo em batelada e a outra é o processo contínuo em leito fixo, na forma de coluna preenchida (FACCINI, 2008). Outra vantagem para a utilização da purificação a seco é a possibilidade da reutilização do adsorvente por técnicas como volatilização térmica, utilização de solventes orgânicos e regeneração química (MARTIN E NG, 1987).

\section{OBJETIVO}

Este trabalho tem como objetivo analisar amostras obtidas a partir da purificação de biodiesel proveniente do óleo de canola bruto, utilizando como adsorvente o carvão ativado em batelada e com diferentes tamanhos de partículas.

\section{MATERIAIS E MÉTODOS}

A matéria-prima de produção de biodiesel foi o óleo de canola bruto fornecido pela Cocamar Cooperativa Agroindustrial, localizada na cidade de Maringá-PR. Para a caracterização da mesma, foram feitas algumas análises que estão listadas a seguir.

Massa Específica a $20^{\circ} \mathrm{C}$ : Foram feitas análises de massa específica na temperatura de $20{ }^{\circ} \mathrm{C}$, utilizando um densímetro digital da marca Atom Paar modelo DMA 5000.

Acidez e Índice de Saponificação: Utilizou-se da metodologia apresentada pelo Instituto Adolfo Lutz (2008) para a determinação da acidez e índice de saponificação.

Perfil de Ácidos Graxos: A matéria-prima foi sobmetida à análise em um cromatógrafo da marca Thermo Scientific, modelo Trage GC Ultra, com uma coluna da marca SGE 
Analytical Science, modelo BPX 70, para análise do perfil de ácidos graxos.

A produção de ésteres etílicos foi realizada com base nos resultados de Gomes et al. (2015). A reação foi realizada na temperatura de $30{ }^{\circ} \mathrm{C}$, razão molar óleo:etanol de 1:7,5 e catalisador $(\mathrm{NaOH}) 1 \%(\mathrm{~m} / \mathrm{m})$ em relação ao óleo de canola, tempo reacional de 1 hora e rotação de $300 \mathrm{rpm}$. Os ésteres produzidos foram levados a um evaporador rotativo sob vácuo e temperatura de $65^{\circ} \mathrm{C}$, para a evaporação do álcool, a mistura resultante foi colocada em funil e deixada em repouso para a separação de fases. O sobrenadante eram os ésteres que foram, então, separados da glicerina.

Para a caracterização dos ésteres analisaram-se a massa específica a $20{ }^{\circ} \mathrm{C}$ e teor de glicerol livre.

Teor de Glicerol Livre: O teor de glicerol livre dos ésteres foi determinado pela metodologia modificada AOCS Ca (14-56), sugerida por Dantas (2006).

Adsorvente Utilizado e suas Características: Carvão ativado mineral de origem betuminosa obtido pelo fabricante Alphacarbo Carvão Ativado, com área específica de 817 $\mathrm{m}^{2} \cdot \mathrm{g}^{-1}$ e volume de meso e microporos de $0,06918 \mathrm{~cm}^{3} \cdot \mathrm{g}^{-1}$ e $0,4078 \mathrm{~cm}^{3} \cdot \mathrm{g}^{-1}$ respectivamente.

Análise Granulométrica: A análise granulométrica ocorreu por peneiramento, utilizando-se peneiras de Tyler-Mesh 8, 10, 14 e 20.

A purificação dos ésteres etílicos foi realizada de duas metodologias diferentes, listadas a seguir.

Método Tradicional: A purificação tradicional dos ésteres etílicos foi realizada pela metodologia proposta por Geris et al. (2007).

Adsorção em batelada: Para a adsorção de glicerol do biodiesel, amostras com $5 \%$ de adsorventes a $65^{\circ} \mathrm{C}$ e $90 \mathrm{rpm}$ foram realizadas e quantificadas o teor de glicerol livre das mesmas, antes e depois da adsorção em diferentes diâmetros médios de partículas do carvão ativado.

\section{RESULTADOS E DISCUSSÃO}

\subsection{Caracterização da Matéria-Prima}

Os valores obtidos para a caracterização físico-química do óleo bruto de canola podem ser encontrados na Tabela 1.

Tabela 1 - Característica físico-química do óleo de canola bruto

\begin{tabular}{|c|c|c|}
\hline $\begin{array}{c}\text { Acidez } \\
(\%)\end{array}$ & $\begin{array}{c}\text { Índice de Saponificação } \\
(\mathrm{mg} \mathrm{KOH} / \mathrm{g} \text { óleo })\end{array}$ & $\begin{array}{c}\text { Massa Específica a } 20^{\circ} \mathrm{C} \\
(\mathrm{g} / \mathrm{mL})\end{array}$ \\
\hline $2,67 \pm 0,02$ & $204,00 \pm 3,00$ & $0,92 \pm 0,00$ \\
\hline
\end{tabular}


Na Tabela 2 estão ilustrados os resultados da cromatografia realizada para o óleo de canola bruto.

Tabela 2 - Composição percentual em ácidos graxos para o óleo de canola bruto

\begin{tabular}{|c|c|}
\hline Ácidos graxos & Composição $(\% \mathrm{~m} / \mathrm{m})$ \\
\hline Palmítico & 4,57 \\
\hline Esteárico & 2,65 \\
\hline Oleico & 63,79 \\
\hline Linoleico & 18,86 \\
\hline Linolênico & 9,28 \\
\hline Outros & 0,85 \\
\hline
\end{tabular}

A partir da composição em ácidos graxos obtidas para o óleo de canola bruto obteve-se a massa molar do óleo de 867,83 g/mol.

\subsection{Caracterização dos ésteres etílicos produzidos}

Obteve-se o valor de massa específica a $20^{\circ} \mathrm{C}$ para os ésteres produzidos de $(0,872 \pm$ $0,000)(\mathrm{g} / \mathrm{mL})$, esse valor quando comparado com o do óleo utilizado na sua produção demonstra que a densidade diminuiu. Também verificou-se o teor de glicerol resultante da reação de transesterificação com valor de $(0,097 \pm 0,003)(\% \mathrm{~m} / \mathrm{m})$.

\subsection{Caracterização do carvão ativado}

Na Tabela 3 são mostradas as três faixas de tamanho utilizadas para o carvão, juntamente com o diâmetro médio de Sauter de cada faixa.

Tabela 3 - Diâmetro médio de Sauter para o carvão ativado.

\begin{tabular}{|c|c|c|}
\hline Faixa de tamanho (Mesh) & Classificação da amostra & Diâmetro médio de Sauter (mm) \\
\hline$-6+10$ & Grossos & 2,06 \\
\hline$-6+20$ & Médio & 1,49 \\
\hline$-10+20$ & Finos & 1,21 \\
\hline
\end{tabular}

\subsection{Purificação do biodiesel}

Os ensaios de adsorção com carvão ativado realizados com diferentes granulometrias levaram a obtenção do gráfico conforme mostra a Figura 1. 
Figura 1 - Porcentagem de remoção do glicerol em função do diâmetro de partícula.

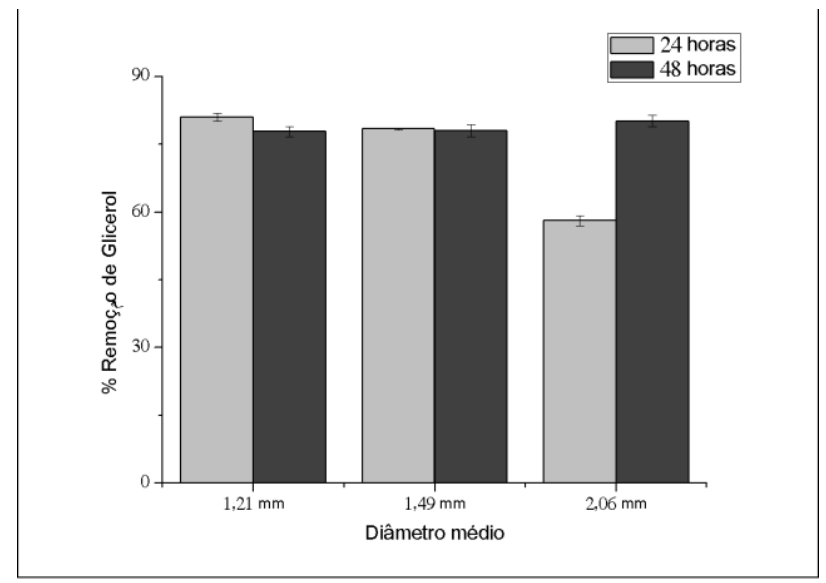

A partir da Figura 1 podemos notar que os valores de grau de remoção do glicerol quando utiliza-se diâmetro 1,21 mm (Finos) e 1,49 mm (Médio) são muito próximos para os tempos de 24 horas e 48 horas. Já para diâmetro 2,03 mm (Grossos), há diferença entre o tempo de 24 horas e 48 horas, o que pode ser devido a menor superfície específica do mesmo em comparação com os Médio e Finos. A maior remoção de teor de glicerol (80\%) foi obtida nas amostras com diâmetro médio do carvão ativado de $1,21 \mathrm{~mm}$ e 24 horas. Na Tabela 4 são apresentados os valores de teor de glicerol no éster após purificação pelo método tradicional e pelo método proposto neste trabalho. A partir dos dados de $1,21 \mathrm{~mm}$ e 24 horas do gráfico ilustrado na Figura 1 e com os valores de teor de glicerol obtidos pelo método tradicional, pode-se construir a Tabela 4.

Tabela 4 - Teor de glicerol para os ésteres produzidos após a purificação

\begin{tabular}{|c|c|c|}
\hline Método & Teor de glicerol $(\% \mathrm{~m} / \mathrm{m})$ & Obs \\
\hline Tradicional & $0,017 \pm 0,003$ & \\
\hline Adsorção & $0,018 \pm 0,001$ & Carvão com tamanho 1,21mm e 24 de adsorção \\
\hline
\end{tabular}

Pela ANP, o teor máximo de glicerol admitido para comercialização do biodiesel é de $0,02 \%$. A tabela acima mostra que ambos os métodos de purificação atendem a especificação da ANP.

\section{CONCLUSÃO}

Pode-se concluir a partir desse trabalho que não houve diferença significativa no percentual de remoção de glicerol comparando-se quando utilizadas partículas com diâmetro médio de Sauter de 1,21 e 1,49 mm. A maior remoção de teor de glicerol foi obtida nas amostras com diâmetro médio do carvão ativado de 1,21 mm e 24 horas.

Sendo assim, o método de purificação tradicional pode ser substituído pela adsorção com carvão ativado com diâmetro de $1,21 \mathrm{~mm}$, já que ambos obtiveram valores de teor de glicerol dentro das normas especificadas pela ANP $(0,017 \%$ e $0,018 \%$, respectivamente). 


\section{REFERÊNCIAS}

AGÊNCIA NACIONAL DO PETRÓLEO, GÁS NATURAL E BIOCOMBUSTÍVEIS. Lei $\mathrm{n}^{\circ}$ 13.033, de 24.9.2014 - DOU 25.9.2014 Disponível em: <http://nxt.anp.gov.br/NXT/gateway.dll/leg/leis/2014/lei\%2013.033\%20\%202014.xml?fn=do cument-frameset.htm $\$ \mathrm{f}=$ templates $\$ 3.0>$. Acesso em 12. Dez. 2015.

DANTAS, Manoel Barbosa. Obtenção, caracterização e estudo termoanalítico de biodiesel de milho. 2006. Dissertação (Mestrado em Química - Centro de Ciências Exatas e da Natureza), Universidade Federal da Paraíba, João Pessoa, 2006.

FACCINI, C. S. Uso de Adsorventes a Purificação de Biodiesel de Óleo de Soja. 2008. 68 f. Dissertação (Mestrado em Química) - Universidade Federal do Rio Grande do Sul, Porto Alegre, 2008.

GERIS, R.; SANTOS, N. A. C. dos; AMARAL, B. A; MAIA, I. S.; CASTRO, V. D.; CARVALHO, J. R. M. Biodiesel de soja - Reação de transesterificação para aulas práticas de química orgânica, Quim. Nova, vol. 30, no. 5, 1369-1373, 2007.

GOMES, M. C. S.; ARROYO, P. A.; PEREIRA, N. C. Influence of oil quality on biodiesel purification by ultrafiltration. Journal of Membrane Science, n. 496, p.242-249, 2015.

INSTITUTO ADOLFO LUTZ. Métodos físico-químicos para análise de alimentos. Coordenadores Odair Zenebon, Neus Sadocco Pascuet e Paulo Tiglea, $4^{a}$ edição, São Paulo: Instituto Adolfo Lutz, 2008.

MARTIN, R. J.; NG, W. J. The repeated exhaustion and chemical regeneration of activated carbon. Wat. Res., vol 21, no. 8, 961-965, 1987.

MEHER, L. C.; SAGAR, D. V.; NAIK, S. N.; Technical aspects of biodiesel production by transesterification - a review . Renew. Sustain. Energy Rev. 2004, 10, 248-268.

MINISTÉRIO DA AGRICULTURA. Produção de canola cresce $65 \%$ na safra 2010/2011. Portal Brasil, 2011. Disponível em: <http://www.brasil.gov.br/economia-eemprego/2011/02/producao-de-canola-cresce-65-na-safra-2010-2011>. Acesso em 21 Out. 2015.

PAUlA, A. J. A. de; KRÜGEL, M.; MIRANDA, J. P.; SANTOS ROSSI, L. F. dos; COSTA NETO, P. R. da. Utilização de argilas para purificação de biodiesel. Quim. Nova, vol. 34, no. 1, 91-95, 2011.

PORTAL DO MINISTÉRIO DA CIÊNCIA, TECNOLOGIA E INOVAÇÃO. Lei n. 11.097, de 13/01/2005. Disponível em: <http://www.mct.gov.br/index.php/content/view/2698.html>. Acesso em 21 Out. 2015.

SANTANA, G. C. S.; MARTINS, P. F.; SILVA, N. L.; BATISTELLA C.B.; FILHO, R.M.; MACIEL, M.R.W. Simulation and cost estimate for biodiesel production using castor oil. Chemical Engineering Research and Design, 88 (2010), pp. 626-632. 